\title{
2. Assembling Platforms: Strategy and Competition
}

\author{
Eric Brousseau and Thierry Pénard
}

\section{INTRODUCTION}

Strategic behaviour in digital markets is difficult to interpret as these industries compete via alternative business models, rather than competing via an accepted business format. For example, in the automotive industry most firms rely on price and product differentiation to compete while the underlying logic of value creation remains the same. This approach contrasts with digital markets where players exploit different business formats to develop customer relationships. For example, certain services may be provided free while similar services are not. Digital market strategies are also more sophisticated and dynamic along product positioning and pricing, alliance, merger and acquisition, and innovation activity dimensions.

Industrial organisation (IO) methods provide a conceptual framework to analyse IT markets by focusing on network externalities and monopolising strategies (Economides, 1996; Varian, 2000). This literature is enriched by the economics of intermediation (Spulber, 1996, 1999, 2003), information (Shapiro and Varian, 1999), and two-sided markets (Rochet and Tirole, 2002, 2003, 2007). However, this literature is mute on business model design, whereby entrepreneurs decide the customers targeted. While the managerial literature provides case study analysis of successful digital business model developments, it lacks a common analytical framework enabling an understanding of commonalities, for example, in the design of open-source software platforms, online travel agencies and search engines.

A special issue of the Review of Network Economics in 2007 developed the idea that a common characteristic of digital business models is the reliance on assembling platforms, by which service providers deliver a combination of (matching, assembling and knowledge management) services. 
The design of business models relies on the choice of business format along each dimension. Brousseau and Pénard (2007) highlighted the essential tradeoffs at stake when positioning on these dimensions. Interaction among these dimensions was, however, not considered. Even when matching, assembling and knowledge management decisions are taken independently there exist strategic synergies between these dimensions that determine the global design of the business model. For instance, being a single counter in a market increases capability to capture information to increase operational quality, which reinforces the firm's unique assembler/matchmaker status.

Based on the analytical framework of Brousseau and Pénard (2007), this chapter analyses key variables to be considered in the design of digital business models. First, the trade-offs specific to matching, assembling and knowledge management are presented. Then, the strategic interdependency among these dimensions is related to the main features characterising demand: heterogeneity in users preferences, willingness to pay for quality, and organised solidarity among users. Furthermore, the firm's challenge is not only to establish a market niche or to obtain a gatekeeper position, since in an industry characterised by permanent innovation and a 'winner-takes-all' race firms must add new functions to their portfolios in an ongoing manner. Such 'agility' or adaptability is required to preserve competitive advantage. The inherent difficulty in managing innovative capability and commercial image, when the supply of services is continually being extended to new domains (that require new capabilities and the evolution of commercial practice) are also underlined. The framework attempts to identify the principal trade-offs among alternative digital strategies. The analysis also stresses the importance of uncertainty regarding digital market competition due to the threat of market invasion by rivals. Rivalry can spoil market positioning because of interdependency among business models due to direct network externalities and competitors' indirect revenues.

\section{ANALYSING DIGITAL BUSINESS MODELS}

This section develops a representation of digital good production and distribution processes to identify the essential dimensions of digital business models, with a view to using these criteria to distinguish alternative models.

\section{Digital Activities as Modular Activities}

The central question addressed is what are the essential demand and supply characteristics of digitally-intensive goods? Three observations are made. 


\section{Observation 1}

Digital goods are modular with basic components (corresponding to functionalities) assembled to meet consumer needs. That is, digital consumer goods are comprised of 'packages' of basic functions.

This notion is consistent with Lancaster's (1979) view that the basis of consumer choice is attributes (components) that comprise final goods. A particular combination of digital content and information processes defines a unique composite good. How digital good packages are assembled distinguish digital business models. Moreover, competition may occur via: (a) a single need being met by alternative packages; or (b) a package being assembled through alternative (organisational) processes. This latter process leads to competition among organisational models.

\section{Observation 2}

Digital activities are characterised by the basic operations:

a) The production of functionalities (modules). Functionalities are linked to the provision of tangible goods or information services, or their combination.

b) The assembly of functionalities. Each module has no independent value. Functionalities are multipurpose, and must be combined to produce a good valued by particular user groups.

c) The consumption of goods generates value (either through consumer satiation or the generation of new goods or knowledge by producers).

That is, digital goods are comprised of multipurpose components that can be employed in several goods. However, the components only have value when combined to produce desired services.

\section{Observation 3}

Consumers are not neutral in the value creation process, since they are able to assemble the functionalities and to generate information or knowledge.

Digital technology is a set of integrated techniques that rely on a common principle: transformation signals - whatever form (voice, image or text) and nature (content or algorithm) - into a set of digits that are processed and transmitted by technical systems. This process generates a de facto meta standard interface that allow integration and interoperability of digital sequences and information processing devices. Agents that integrate different 
digital components must manage interfaces; that is, gateways and translators. When universal interface standards and protocols exist, for example, the Internet, assembly of components is straightforward. Interoperability among components is more costly when more than interface management is required. Often, components are designed to be compatible with other components, viz., mutual specialisation (asset specificity as per Williamson, 1985). Compatibility allows consumers to assemble products, for example, open-source software. When consumers assemble products, potential competition exists with specialists (platforms).

Second, in an information market, supply and demand sides are difficult to disentangle as consumers use and create information. Situations range from consumer spontaneous feedback to innovation derived from learning, including service adaptation to better match needs (Henkel and von Hippel, 2005). Actively or passively, consumers generate valuable information on service quality and product design. That is, consumers are viewed as intermediate good producers via information good consumption. This view applies to open source software communities that invent around existing code. Therefore, potential exists for producers of functionality and consumers to cooperate to produce information. Consumers also provide assemblers with information enabling more efficient customer targeting.

Figure 2.1 depicts digital markets via agent relationships: producers, assemblers and consumers. Consumers buy functionality packages directly from producers or through assembling platforms. Consumption generates information that improves capabilities of producers or assemblers. Transactions are organised by agents based on expected benefit and cost, with platforms coordinating both sides of the market.

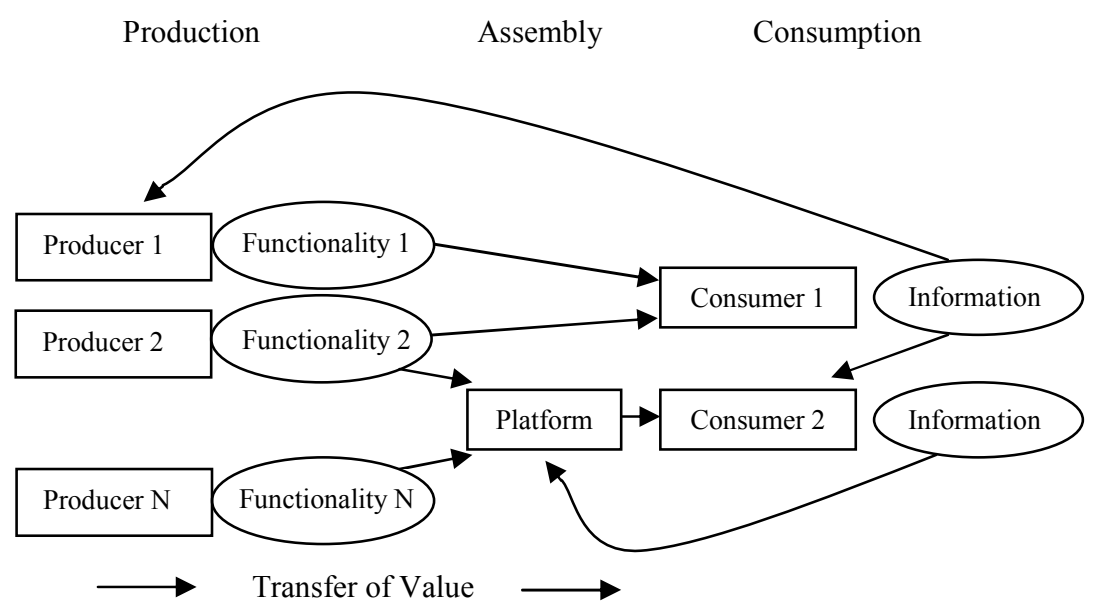

Figure 2.1 Analytical framework 
The remainder of the chapter considers options available to platforms to deliver matching, assembling and knowledge management services.

\section{Business Model Dimensions}

Being a mix of matching, assembly, and knowledge management, the economics of digital business models refers to three logics. The economics of matching focuses on transaction costs and examines the way to improve market fluidity and to tackle transaction security and risk management difficulties. The economics of assembling focuses on assembly cost and compatibility issues. Assembling platforms enable interoperability among functionalities and the extraction of value from consumers. Finally, the economics of knowledge management examine how information generated by digital good consumers improves quality of service and supports innovation. The approach considers that digital networks enable information sharing, and so modify the capability to share information, and distribute knowledge.

Figure 2.2 depicts pure business models on the corners, that is, pure matching (e.g., dating services), knowledge management (e.g., online epistemic communities) or assembly (e.g., telecommunications access provider). The surface corresponds to service combinations. For instance, online travel agencies (located in the central area of the surface) typically provide a mix of services by identifying providers (matching), managing knowledge (e.g., customer and guide rankings) and providing a combination of services (transport, car rental, hotel reservations, and access to entertainment services). Whereas, eBay for instance, which provides a mix of matching and knowledge management services, is located on the right edge of the triangle.

Importantly, the decisions depicted at each corner of the triangle are independent. That is, assembly strategies are distinct from knowledge management choices. They do not highlight the same trade-offs (as illustrated by the two axis pointing out the space of choice at each summit of the triangle). In choosing how they manage their operations along the three dimensions depicted in the triangle, platforms establish their business models. Finally, each possible business model can be dominated by a firstmover monopolist because of network externalities, fixed cost effects, increasing return of adoption, etc. (Shapiro and Varian, 1999; Varian, 2000; Hand, 2001). Competition is therefore between business models rather than within business models. This structure is illustrated by the competition between Linux and Microsoft (McKelvey, 2001), Amazon and eBay, and Google and Yahoo! 


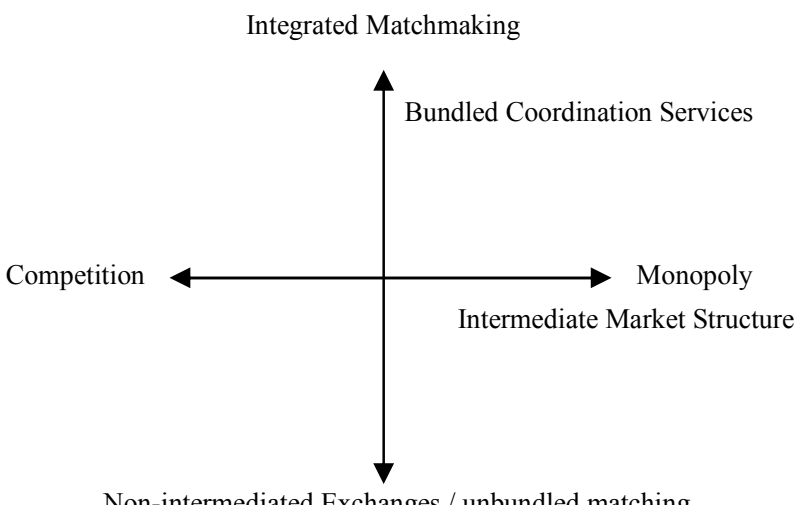

Non-intermediated Exchanges / unbundled matching
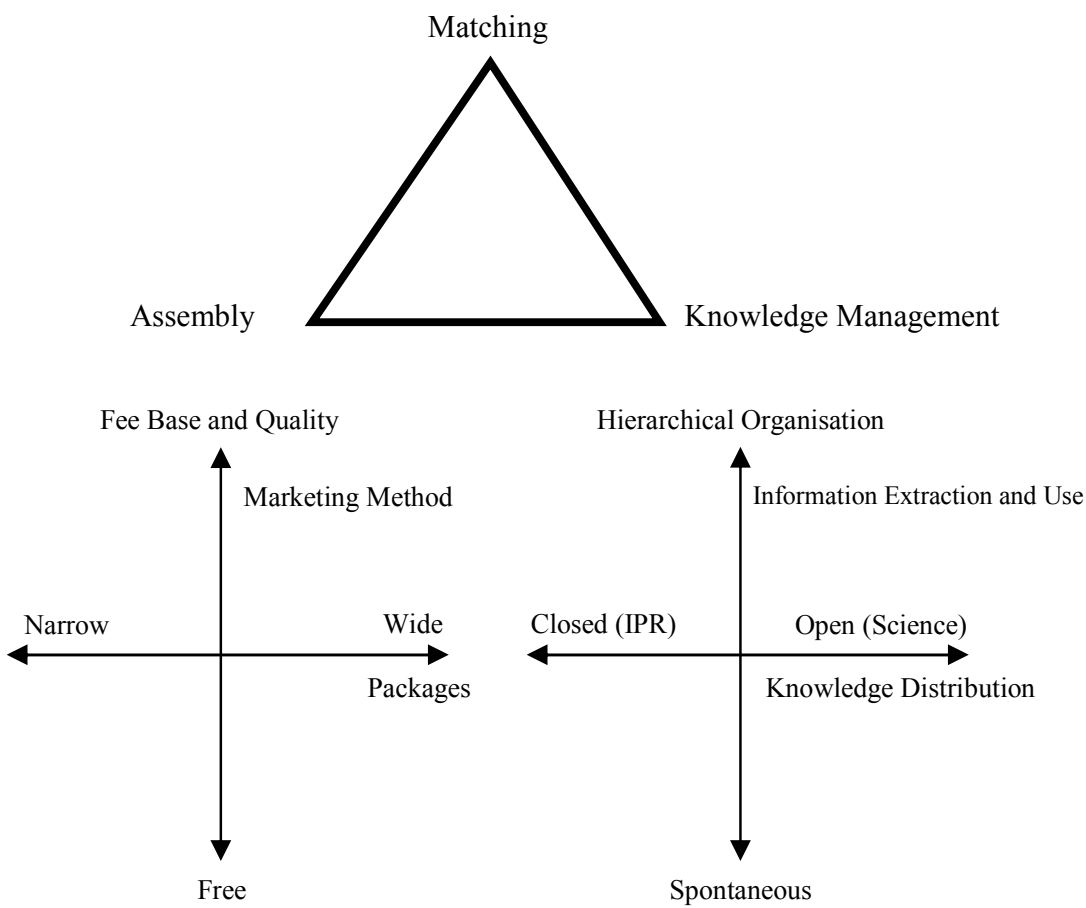

Figure 2.2 Digital business model dimensions 
The approach differs from the received literature that analyses firm-level business models by considering how investment in online service provision (intensity, diversity and timing), and marketing strategies should be implemented (pricing, customer loyalty management, portfolio provision) to guarantee a satisfactory return on investment (see Melo de Brito Carvalho and Siegel (2002) for online banking). Also, the analysis departs from Varian and Shapiro (1999), who mostly focus on pricing information and managing lock-in. The current approach focuses on the coordination agents involved in the production and use of information, and network-based services by examining horizontal and vertical co-opetition along transaction chains, and analysing how value is created and shared to result in sustainable models.

\section{BUSINESS FORMAT CHOICE}

A digital business model is a combination of the roles played by platforms. A platform can be a pure market intermediary (e.g., dating service), assembler (e.g., online media company), knowledge manager (e.g., Wikipedia community), or paired (e.g., eBay, Google and Yahoo!) or provide all functions (e.g., online travel agency). Accordingly, platforms are positioned in the triangle and a service level is chosen for the functions. Knowledge management, for instance, varies by quality: the platform provides a simple link or advanced services (e.g., storage and indexing) between users. The service provided depends on consumer willingness to pay and improved quality marginal cost.

Brousseau and Pénard (2007) analyse format choice by dimensions that characterise digital business models (matching, assembly and knowledge management). Here, these trade-offs are viewed as linked to customer preference and rival strategy. In particular, successful matching depends on platform competition that influences the extent of cross-subsidisation and centralisation of information. Also, assembly positions depend on consumer willingness to pay for integration and on the positioning of competitors. Finally, knowledge management style relies on the ability to organise and mobilise consumers.

\section{Matching Format and Market Structure}

For matching, options include integrated intermediaries providing packaged service or several firms providing unbundled intermediation service (that is, information, matching, transaction securisation, market clearing; see Brousseau, 2002). The optimal structure depends on consumer intermediation costs (willingness to pay for external intermediation) and ability to provide unbundled intermediation services (for example, information matching 
alone). The less standard are intermediation service provider interfaces and the less efficient technology to provide unbundled services, the more integrated are intermediation market platforms. Integrated intermediaries benefit from synergy among intermediation functionalities. However, their inclination to capture rents reduces their attractiveness to end-users. Accordingly, there should be equilibrium between integrated platforms, preempting core market and unbundled intermediation service providers that target market segments. Consumers with the lower assembly costs (for intermediation services) are more likely to contract with unintegrated intermediaries. Users can be more efficient in assembly when they demand a large volume of intermediation services or when they can dedicate and specialise assets. In particular, professional users favour unbundled intermediaries that challenge integrated platforms at the professionalconsumer market borders, Finally, direct competition among integrated platforms affects the capability to cross-subsidise both sides of the market and provide efficient intermediation service. More competition among integrated intermediaries reduces competitive advantage over unbundled intermediation service providers. The only stable competitive equilibrium is between a dominant integrated platform and unbundled intermediation service providers.

\section{Diversity and Integration Preferences}

Assembly strategies differ by the modules assembled and marketing method. Assemblers must decide how many modules to include in packages. Narrowly defined packages more effectively meet consumer needs, better enable integration and interoperability, increase the value obtained from modules and reduce assembly cost. However, universal interface standards, a feature of the Internet environment, provide an incentive to offer more assembled packages (increase competition among assemblers). This outcome lowers integration (as interoperability is imperfect), reducing differentiation and lowering market power.

Assembly strategy depends on marketing methods and vice versa. Since securing information service access and excluding non-payers are costly, assemblers may rely on indirect revenue from collecting information about consumer characteristics and behaviour. In this case, advertising and the reselling database services (from tracking and analysis of online behaviour) are relied upon. Conversely, platforms can secure access to packages. Here, revenue arises from fee-based service provision. Free service provision leads to maximisation of the audience, since advertising and database revenues are highly correlated with the platform coverage. When consumer preferences differ, platforms assemble many modules. However, increasing service offerings reduces the assembly quality and profitability. Because of satiation 
and time constraints, integrating more modules into platforms raises user search costs without increasing consumer utility, especially when package 'enrichment' results from aggregating close substitutes. Moreover, integration cost rises with the number of modules, adversely impacting on assembly platform costs. With free provision lowering quality and raising costs a niche exists for providing similar services on a fee-paying basis. When it is not too costly to exclude free-riders providing highly integrated and targeted (seamless) sets of modules is profitable. The approach is differentiated by offering reliable, accessible, user-friendly and customised services. Fees must cover higher assembly costs. Consumer preferences for diversity, willingness to pay for quality and interoperability (high quality assembly), and secure access to information services are important variables in assembling strategies. These parameters determine market shares of providers of free, wide-range packages of information services, and niche providers of highly integrated and targeted value-added digital services (Brousseau and Pénard, 2007).

\section{Knowledge Management and Innovation}

Platforms also manage information generated by consumers. There are two dimensions. First, the various tasks (collecting, storing, exploiting information) have to be organised to avoid duplication, stimulate collaboration and prioritise objectives. Second, incentives have to be managed to avoid generalised free-riding (non-contribution to a public good).

When contribution value varies substantially across users, a pyramid organisational structure is appropriate, as only a small share of contributors has to be organised, implying smaller organisational costs. When contribution values are unequally distributed, only the most valuable contributors have to be included in the innovation process ('standing on the shoulders of giants' effect; cf. Scotchmer, 1991). The capability of organising the process of contribution thus strongly depends upon the distribution of competences among contributors.

The desirability of incentive management also depends upon the characteristics of contributions and contributors. The best way for the platform to efficiently manage the process of innovation/information circulation is to manipulate the individual incentives of users. There are, however, two hampering sources. First, it is a complex task to modify incentive mechanisms and to evaluate their impact on users' contributions. It requires perfect monitoring of individual behaviour and a good understanding of the collective process of innovation. The value of innovation and knowledge production depends on multiple contributions that are different in nature and yield uncertain outcomes. Second, modifying incentive mechanisms can be counterproductive. Indeed, a 'crowding out' effect can arise if incentives collide with intrinsic motivation (altruism, fairness, etc.) 
(Frey and Oberholzer-Gee, 1997; Fehr and Gächter, 2002; Benabou and Tirole, 2003, 2007). More simply, since innovation is a multi-task problem, an incentive scheme can distort the activity of contributors.

Given the relatively low marginal value of each contribution to a collective innovation, the full individualisation of incentives through the establishment of an intellectual property rights system is of little use most of the time in the users' based processes of innovation. In addition, it is often difficult to monetise the innovations resulting from such processes because they translate into higher quality of service, which does not systematically yield additional revenues (when competition is intense between innovators). Lastly, transaction costs could result in a tragedy of the anti-commons (Heller and Eisenberg, 1998). Since digital technologies tend to facilitate the management of customized access to information services, enhanced services and/or privileged or prior access are means to incite contributors.

Another way to reduce the costs of incentives is to rely on users to oversight contributors' activity, punish the free-riders and reward the best contributors. Hence, the promotion of 'communities' by many platforms. Here the issue is to determine whether the community is independent of the tools provided by the platform. In very large and loose communities-like the community of eBay users - the technical platform enabling management of traders' reputations is a key asset well secured in the hands of the service provider. In other cases where the latter is hosting a community that preexisted, or that relies on strong and intertwined links among members, the service provider is unable to extract the value created by the community, because the latter can always switch to another platform.

\section{MATCHING, ASSEMBLY AND KNOWLEDGE}

Positioning a platform on each side of a sub-market depends on the:

(a) Capability to quasi-monopolise matching (either market segment or niche);

(b) Distribution of consumer assembly preferences for customised, highly-integrated service as opposed to free access but lower quality service (containing advertising content while assembly costs borne by consumers); and

(c) Knowledge generation process, whether radical and communities are self-organising. 
However, platforms in positioning on the market corresponding to one of these three dimensions can lever competitive advantage to establish positions in another market.

The competitive advantage of a matchmaker can either draw from firstmover advantage or from the establishment of a monopoly position on the other markets. In the first case, it is a path dependency effect: the platform that was able to impose itself as the main player at some stage of the development of a matching market remains the un-bypassable infomediary. In the second case, the platform provided initially another type of service and relies on its ability to be an intermediary between the two sides of the market to provide matching services.

In matter of assembling, the capability to become an assembler depends on the position on the two other markets (matching and knowledge managements). A dominant matchmaker or knowledge platform will have a natural tendency to enter the assembling market (leverage strategy). A dominant information broker can indeed use its position on a specific market to assemble other services. In that case, however, it can only choose the freeloose model of assembling, since it has to remain a central and open platform on its core market. This is typically the strategy followed by Google. A knowledge aggregator can, and is likely to, adopt an opposite strategy. If it provides an epistemic community with the capability to share and aggregate knowledge, it can provide additional services to enhance the service provided to this community and will be eventually able to charge for them. While it will be in dominant position, the platform will however be in a highly contestable situation since the community can at any time decide to switch to another provider if the assembler tries to extract too much rent.

In matter of knowledge management, the possibility to become a knowledge organiser - that is, a platform that manages the production and the incentives of contributors - does not really depend upon the positioning on the other markets. It depends first and foremost upon the characteristics of the knowledge creation process and upon the technical capability to provide a platform well adapted to the users-contributors' needs. There are therefore more examples of platforms sustaining epistemic communities enlarging their service provision than matching or assembling platforms progressively enlarging their provision to knowledge management.

The capability to become an information aggregator - that is, a platform that produces knowledge through the simple tracking of users' behavioursis however highly linked to the capability of becoming a dominant matchmaker or a dominant assembler. In both cases, being a bottleneck at the centre of a market allows maximising the number of contributions, and therefore the value of the user generated knowledge. 


\section{RESHAPING MODELS}

To this point the trade-offs firms face in digital business model positioning are the only platform strategy dimensions. However, platforms must also consider the best means to manage: (a) innovation; and (b) public image and brand. Digital market competition is based on the provision of reliable and well-priced service and the development of new functionalities. Indeed, competitors, entrants and innovators are continually inventing new features and ways of combining services. A strategy available to platforms is selfdevelopment, which implies the continual enhancement of innovative and time-to-market capabilities. This strategy is employed by dominant firms such as Google and Microsoft. However, this is a strategy that is only available to adequately resourced market leaders. The only strategy available to non-dominant players is the acquisition of new capability through mergers and acquisition (M\&A). M\&A are a means to secure access to functionalities or assembly capabilities essential to dominate a market segment. From the firms point of view it is essential to integrate the acquired functionalities into a meaningful service from a consumer perspective. However, most digital services generate unintended uses as consumers experiment with the technology. That is, the marketing of innovations usually consist of backand-forth exchanges between the sides of the market by a process of trial and error. In the short run successful integration is essential since competition is based on the capability to innovate around available services. This requirement necessitates the integration of teams from different and competing organisations, challenging the success of M\&A strategies.

Another challenge is managing site and platform reputation. In digital markets competitors are a 'one-click' away, and even in the presence of positive switching costs (cf. Shapiro and Varian, 1999), consumers can easily switch to alternative providers. Accordingly, platform reputation is important as services are often relation-based in nature and characterised by direct network externalities. Furthermore, since information services are often experience goods, trust is also of strategic importance. Google and Apple, for instance, successfully developed (different) company images of providing up-to-date, reliable, user-friendly and 'cool' technology to customers. In a polar example eBay recently introduced changes to feedback systems to improve the accuracy of evaluation. The change triggered adverse reactions from sellers that switched to AmazonMarketplace.

\section{STRATEGIC POSITIONING}

As digital markets are characterised by winner-takes-all competition, relatively low switching costs and continual evolution of business models 
that react to rival behaviour, the markets are highly risky and malleable. Current difficulty faced by Yahoo! and eBay illustrate a lack of industry stability. In this context it is hard to adopt durable strategy due to the potential cross effects that interplay between models. For example, the dynamics of adoption can affect competitive positions of business models. Namely, since (direct and indirect) network externalities are important, a model can become less attractive simply because customers switch platforms. This dynamic is reinforced by production synergies whereby larger audiences are attracted to platforms with an extended range of functionalities, which in turn may benefit from stronger matching and knowledge management capability. Also, revenues can be cannibalised. That is, a player relying on particular revenue sources to provide service may deprive rivals of a principal source of revenue without adopting an intentional predatory strategy. This situation can arise from either providing free services or by capturing most indirect revenue sources. For example, Google provides services, such as roaming with regard to e-mail, which compete directly with ISP-provided services. Moreover, Google gathers information on consumers that impacts on the ability of small firms to market data and consumer information.

These effects make strategic positioning fragile as only dominant players are able to structure policy that relies on the synergies and complementarities among components of their service portfolios to alleviate specialised business model risks. Followers' best response is to diversify and rely on alternative revenue sources to avoid cannibalisation of revenue from direct or indirect competition. This is the principal challenge facing current firms operating in digital markets that wish to survive and actively innovate.

\section{ACKNOWLEDGEMENTS}

The authors received financial support from France Télécom Research and Development, and from the European Union (DG Research as part of the 'Ref-Gov' Integrated project). We would like to warmly thank all these sponsors. Useful comments were received from participants to conferences and workshops organised by the ITS. The usual caveats apply. 


\section{REFERENCES}

Benabou, R. and Tirole, J. (2003), 'Intrinsic and Extrinsic Motivation', Review of Economic Studies, 70, 489-520.

Benabou, R. and Tirole, J. (2006), 'Incentives and Prosocial Behavior', American Economic Review, 96, 1652-78.

Brousseau, E. (2002) 'The Governance of Transaction by Commercial Intermediaries: An Analysis of the Re-engineering of Intermediation by Electronic Commerce', International Journal of the Economics of Business, 9, 353-374.

Brousseau, E. and Pénard, T. (2007), 'The Economics of Digital Business Models: A Framework for Analyzing the Economics of Platforms', Review of Network Economics, 6, 81-114.

Economides, N. (1996), 'The Economics of Networks', International Journal of Industrial Organization, 14, 673-99.

Fehr, E. and Gächter, S. (2002), 'Do Incentive Contracts Undermine Voluntary Cooperation?', Working Paper Series, Institute for Empirical Research in Economics, University of Zurich.

Frey, B. and Oberholzer-Gee, F. (1997), 'The Cost of Price Incentives: An Empirical Analysis of Motivation Crowding-Out', American Economic Review, 87, 746-55.

Hand, J. (2001), 'Evidence on the Winner-takes-all Business Model: The Profitability Returns-to-scale of Expenditures on Intangibles Made by U.S. Internet Firms, 1995-2001', Working Paper, University of North Carolina.

Heller, M. and Eisenberg, R. (1998), 'Can Patents Deter Innovation?', Anticommons in Biomedical Research Science, 280, 698-701.

Henkel, J. and von Hippel, E. (2005), 'Welfare Implications of User Innovation', Journal of Technology Transfer, 30, 73-87.

Lancaster, K. (1979), Variety Equity and Efficiency, Basil Blackwell: Oxford.

McKelvey, M. (2001), 'The Economic Dynamics of Software: Three Competing Business Models Exemplified through Microsoft, Netscape and Linux, in Innovation in the Telecommunication Industry', Economics of Innovation and New Technology, 11, 127-64.

Melo de Brito Carvalho, T. and Siegel, M. (2002), 'Return on Investment from Online Banking Services: An Analysis of Financial Account Aggregation', MIT Sloan Working Paper No. 4384-02, Sloan School of Management.

Rochet, J. and Tirole, J. (2002), 'Cooperation among Competitors: Some Economics of Payment Card Associations', Rand Journal of Economics, 33, 549-70.

Rochet, J. and Tirole, J. (2003), 'Platform Competition in Two-sided Markets', Journal of the European Economic Association, 1, 990-1029.

Rochet, J. and Tirole, J. (2007), 'Two-sided Markets: A Progress Report', Rand Journal of Economics, 37, 645-67.

Scotchmer, S. (1991), 'Standing on the Shoulders of Giants: Cumulative Research and the Patent Law', Journal of Economic Perspectives, 5, 29-41.

Shapiro, C. and Varian, H. (1999), Information Rules: A Strategic Guide to the Network Economy, Harvard Business School Press: Cambridge.

Spulber, D. (1996), 'Market Microstructure and Intermediation', Journal of Economic Perspectives, 10, 135-52.

Spulber, D. (1999), Market Microstructure: Intermediaries and the Theory of the Firm, Cambridge University Press: New York. 
Spulber, D. (2003), 'The Intermediation Theory of the Firm: Integrating Economic and Management Approaches to Strategy', Managerial and Decision Economics, 24, 253-66.

Varian, H. (2000), 'Market Structure in the Network Age', in E. Brynjolfsson and B. Kahin (eds.), Understanding the Digital Economy, MIT Press: Cambridge.

Williamson, O. (1985), The Economic Institutions of Capitalism: Firms, Markets and Relational Contracting, Free Press: New York. 